\title{
Cytocompatibility of Bone Substitute Materials and Membranes
}

\author{
SOGAND SCHAFER ${ }^{1,2^{*}}$, HAYDER AL-QADDO $^{1^{*}}$, MARTIN GOSAU $^{1}$, RALF SMEETS $^{1,2}$, PHILIP HARTJEN $^{1}$, \\ REINHARD E. FRIEDRICH ${ }^{1}$, OLA A. NADA ${ }^{1}$, TOBIAS VOLLKOMMER ${ }^{1}$ and ASHKAN RASHAD ${ }^{3}$ \\ ${ }^{1}$ Department of Oral and Maxillofacial Surgery, \\ University Medical Center Hamburg-Eppendorf, Hamburg, Germany; \\ ${ }^{2}$ Department of Oral and Maxillofacial Surgery, Division of Regenerative Orofacial Medicine, \\ University Hospital Hamburg- Eppendorf, Hamburg, Germany; \\ ${ }^{3}$ Department of Oral, Maxillofacial and Facial Plastic Surgery, \\ RWTH Aachen University Hospital, Aachen, Germany
}

\begin{abstract}
Background/Aim: With the demographic change and associated chronic bone loss, the need for cytocompatible bone replacement materials arise in modern medicine. The aim of this in vitro study was to investigate the cytocompatibility of eleven different bone substitute materials and membranes. Materials and Methods: Seven bone substitute materials and four membranes were assessed in vitro. The specimens were tested based on their interaction with MC3T3 pre-osteoblasts, through the utilization of viability, proliferation, and cytotoxicity assays. Cell vitality was evaluated using live-dead staining. Results: Although we found minor differences in cytocompatibility among the assessed materials, all tested materials can be considered as cytocompatible with a viability of more than $70 \%$ of the negative control, which indicates the non-toxic range as defined in current, international standards (DIN EN ISO 10993-5:2009, German Institute for Standardization, Berlin, Germany). Direct live-dead staining assays confirmed satisfactory cytocompatibility of all tested membranes. Conclusion: All examined bone substitute materials and membranes were found to be cytocompatible. In order to assess whether the observed minor differences can impact regenerative processes, further in vivo studies need to be conducted.
\end{abstract}

This article is freely accessible online.

*These Authors contributed equally to this work.

Correspondence to: Sogand Schäfer, Department of Oral and Maxillofacial Surgery, University Medical Center Hamburg-Eppendorf, Martinistraße 52, Hamburg, Germany. Tel: +49 (0)40741053254, Fax: +49 (0)40741055467, e-mail: sog.schaefer@uke.de

Key Words: Bone substitute materials, guided bone regeneration, guided tissue regeneration, cytocompatibility, biocompatibility.
As a result of the demographic change among western countries, the percentage of the population older than 65 years will increase by $21 \%$ in OECD-countries (Organisation for Economic Cooperation and Development, Paris, France) and even by $29 \%$ by 2030 in Germany. The new challenges arising from the shift towards demographic ageing include an increasing need for osseous regeneration and replacement $(1,2)$.

Osseous regeneration approaches and grafting procedures were already conducted in early 1900 s by Vittorio Putti and contemporaries, who established a significant foundation for further research in this field $(3,4)$. Today, the specialties of oral and maxillofacial surgery and periodontology have a great demand for autogenous bone grafts, allografts, and in particular bone substitute materials (BSM) (5). In contrast to extensive bony defect situations after trauma or ablative tumor surgery, defects that are limited to the dentoalveolar field have great relevance as implantological cases. Examples include: intra-bony/contained defects, vertical alveolar crest defects, maxillary sinus defects, periodontal and peri-implant defects, alveolar socket/ridge preservation.

Furthermore, the importance of BSMs is emphasized with due regard to the burgeoning global market for dental bone substitute materials and membranes, which prospectively will have doubled the value from US \$419 million in 2015 to US $\$ 922.6$ million by $2024(2,6)$.

Looking into the question of which grafting material is suitable for a particular indication, it is crucial to decide not only based on the patient's individual case but also with the different material properties in mind. Many clinical studies have examined autologous bones as the preferred gold standard material followed by allogenous grafts $(5,7,8)$. However, there are reports of donor site morbidity associated with autografts and concerns regarding the transmission of diseases from allografts. In this context, bone substitute materials serve as a promising alternative. BSMs are usually classified in three main groups: natural, synthetic, and composite materials (Table I) $(5,7,8)$. 
in vivo $35: 2035-2040(2021)$

Table I. Tested bone substitute materials and membranes with respective properties due to manufacturer's information.

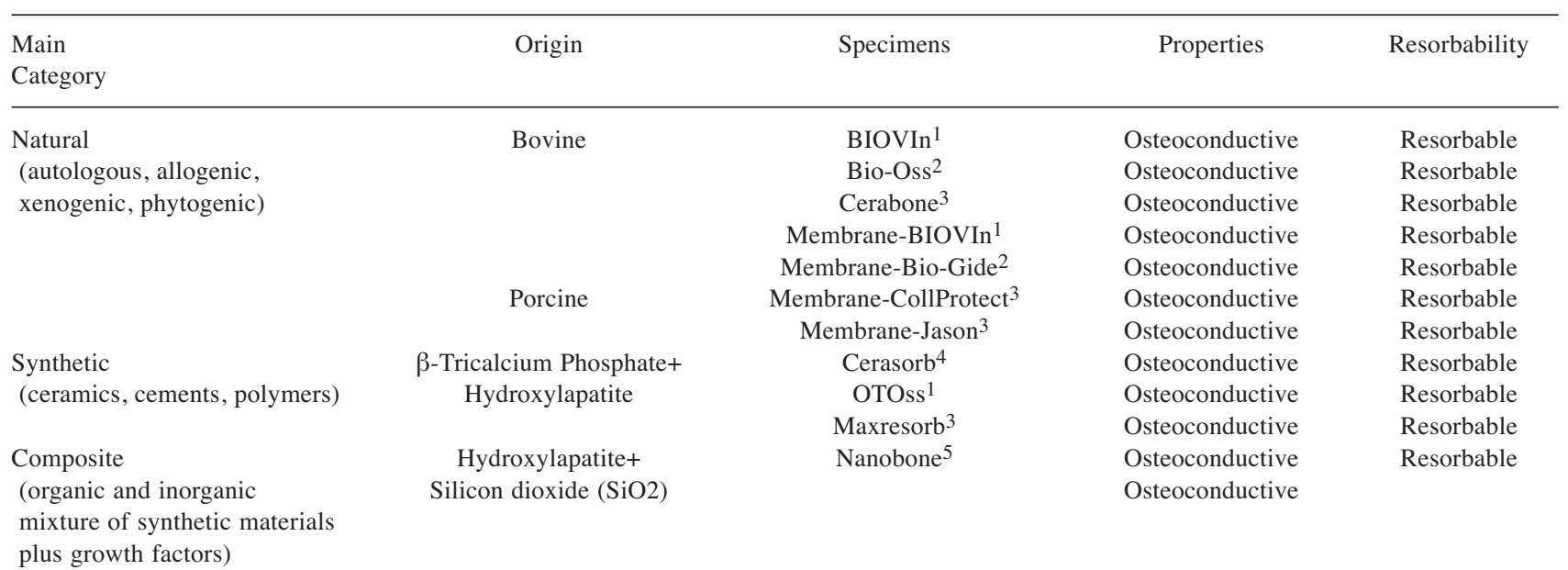

${ }^{1} \mathrm{OT}$ medical, Bremen, Germany; ${ }^{2}$ Geistlich Biomaterials GmbH, Baden-Baden, Germany; ${ }^{3}$ Botiss biomaterials GmbH, Zossen, Germany; ${ }^{4} \mathrm{Curasan}$ Inc, Wake Forest, NC, USA; ${ }^{5}$ ARTOSS GmbH, Rostock, Germany.

Table II. Biological properties of bone grafts.

\begin{tabular}{lc}
\hline Term & Definition \\
\hline $\begin{array}{l}\text { Osteogenic } \\
\text { Osteoinductive } \\
\text { Osteoconductive }\end{array}$ & $\begin{array}{c}\text { Material or tissue which has the ability to build new bone with its containing cells } \\
\text { Mhich due to its structure or contained growth factors is able to initiate and promote bone formation } \\
\text { Material or tissue which promotes the formation of new bone on its own surface } \\
\text { due to its specific surface structure or chemical composition }\end{array}$ \\
\hline
\end{tabular}

In order to guarantee a sustainable bone regeneration, BSMs should meet specified standards. Standards such as those described by Kolk et al. and other studies include biocompatibility, osteoinduction or osteoconduction (Table II), stability under stress, porosity, uncomplicated handling, resorbability/degradability, cost efficiency, plasticity, safety \& sterility, long-term stable integration, and successful implantation (2, 5, 7-9). For long-term success and clinical approval, biocompatibility is one of the key factors. The term describes the ability of the material to develop beneficial features and, at the same time, to behave in a non-toxic, noncarcinogenic, and non-teratogenic manner (2, 5, 7-9).

The path to the clinical or pre-clinical study of every material and medical device usually begins with in vitro cytocompatibility testing (10). Hence, the aim of the following in vitro study was to investigate the cytocompatibility of different bone substitute materials and membranes, each from a subgroup according to the scheme presented in Table I.

\section{Materials and Methods}

Bone substitute materials and membranes. Seven BSM and five membranes applicable for guided bone/tissue regeneration
(GBR/GTR) were evaluated in this study. The selection included materials of bovine Bio-Oss (Geistlich Biomaterials GmbH, Baden-Baden, Germany), Cerabone (Botiss biomaterials GmbH, Zossen, Germany), Membrane-BIOVIn (OT medical GmbH, Bremen, Germany), Membrane-Bio-Gide (Geistlich Biomaterials GmbH), BIOVIn (OT medical GmbH, Bremen, Germany), porcine Membrane-CollProtect (Botiss), Membrane-Jason (Botiss), synthetic Cerasorb (Curasan Inc., Wake Forest, NC, USA), OTOss (OT medical), Maxresorb (Botiss), and Composite origin Nanobone (ARTOSS GmbH, Rostock, Germany). A detailed overview of the test samples is given in Table I.

Reference materials (toxic and non-toxic controls). Ten $\mu \mathrm{M}$ tributyltin chloride (TBTC, Sigma-Aldrich, St. Louis, MO, USA) was used as a toxic control substance. For the indirect assays, medium that was incubated in the absence of specimens was used as a non-toxic control. For the live-dead staining assay, tissue culture coverslips (TCC) (Sarstedt, Nümbrecht, Germany, Cat. No. 83.1840.002) were used as a non-toxic control material. As a toxic control for the live-dead staining assay, cells were seeded on TC coverslips, allowed to attach and subsequently TBTC was added to the attached cells at a final concentration of $10 \mu \mathrm{M}$. Samples of TCC plastic sheets with the same identical surface areas as the material specimens were cut and sterilized as described for the specimens. 

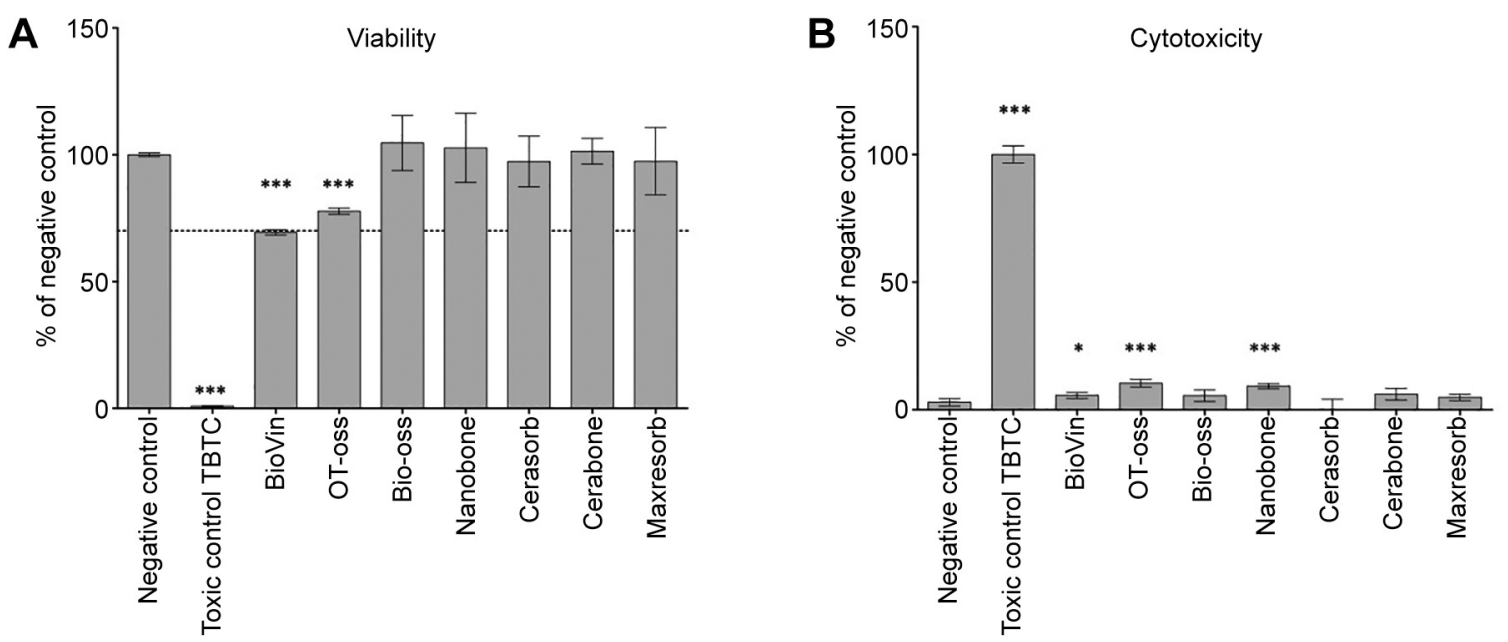

Figure 1. Cytocompatibility of bone substitute materials. A) Viability B) Cytotoxicity. The mean absorbance of controls without cells was subtracted from the mean absorbances. Columns represent mean values of quadruplicate measurements; error bars represent the standard deviation. The dotted line shows $70 \%$ of the negative control. Assays were performed following a $24 \mathrm{~h}$ incubation of MC3T3 cells with extracts of the materials. *, ** and ***: Significantly different from the negative control at $p \leq 0.05, p \leq 0.01$ and $p \leq 0.001$, respectively.

Cell culture. MC3T3 pre-osteoblasts were obtained from the European Collection of Cell Culture, ECACC (Salisbury, UK). Cells were cultured in MEM-alpha supplemented with $10 \%$ fetal bovine serum and penicillin/streptomycin (100 U/ml each) (all from Life Technologies, Carlsbad, USA), in the following referred to as cell culture medium, at $37^{\circ} \mathrm{C}, 5 \% \mathrm{CO}_{2}$ and $95 \%$ humidity (cell culture conditions). Cells were passaged when they reached about $80 \%$ confluency.

Extraction. The bone substitute materials were extracted by saturation with cell culture medium and subsequent addition of medium to a ratio of $0.1 \mathrm{~g} / \mathrm{ml}$. Membrane-specimens were extracted with $3 \mathrm{~cm}^{2} / \mathrm{ml}$ of cell culture medium. All materials were extracted for $72 \mathrm{~h}$ at $37^{\circ} \mathrm{C}$, $5 \% \mathrm{CO}_{2}$ and $95 \%$ humidity (cell culture conditions).

Indirect assay procedure. Assays and in vitro settings were applied as described in our previous work (11), except that MC3T3 cells were used. In brief, 96-well plates (Sarstedt, Nümbrecht, Germany) were seeded with $1 \times 104$ cells/well in $100 \mu$ cell culture medium and incubated under cell culture conditions for $24 \mathrm{~h}$. Thereafter, cell culture medium was discarded and $100 \mu \mathrm{l}$ of extract was added to each well. Cells were further incubated for $24 \mathrm{~h}$ and then subjected to the XTT-assay, while the supernatants were subjected to the LDH-assay.

Viability and proliferation assay. Cells incubated with the extracts were subjected to an XTT-assay. The "Cell Proliferation Kit II" (XTT) (Roche Diagnostics, Mannheim, Germany) was used according to the manufacturer's instructions. Briefly, the electroncoupling reagent was mixed with XTT labeling reagent (1:50 dilution) and $50 \mu \mathrm{l}$ of the mixture was added to the cells. After $4 \mathrm{~h}$ of incubation under cell culture conditions, substrate conversion was quantified by measuring the absorbance of $100 \mu \mathrm{l}$ aliquots in a new 96-well plate using a scanning multi-well spectrophotometer (Microplate Reader, Bio-Rad Laboratories, Inc., CA, USA) with filters for $450 \mathrm{~nm}$ and $650 \mathrm{~nm}$ (reference wavelength).
Cytotoxicity assay. Cytotoxicity was determined using a "LDHCytotoxicity Assay Kit II" (BioVision, Milpitas, CA, USA) according to the manufacturer's instructions. Briefly, $10 \mu \mathrm{l}$ of the cell supernatants were incubated with $100 \mu \mathrm{LDH}$ reaction mix for $30 \mathrm{~min}$ at room temperature. After addition of stopping solution, absorbances were measured using a scanning multi-well spectrophotometer (ELISA reader) with filters for $450 \mathrm{~nm}$ and 650 $\mathrm{nm}$ (reference wavelength).

Live-dead staining assay. In order to perform live-dead cell staining on the surfaces of the membrane specimens, $60 \mu \mathrm{l}$ per ml medium propidium iodide (PI) stock solution $(50 \mu \mathrm{g} / \mathrm{ml}$ in PBS) and $500 \mu \mathrm{l}$ per $\mathrm{ml}$ medium fresh fluorescein diacetate (FDA) working solution (20 $\mu \mathrm{g} / \mathrm{ml}$ in PBS from $5 \mathrm{mg} / \mathrm{ml} \mathrm{FDA}$ in acetone stock solution) were added to each well (12 well plate). After a brief incubation for $3 \mathrm{~min}$ at room temperature, specimens were rinsed in prewarmed PBS and immediately examined with an upright fluorescence microscope (Nikon ECLIPSE Ti-S/L100, Nikon GmbH, Düsseldorf, Germany) equipped with a filter for parallel detection of red and green fluorescence.

Data evaluation. The mean absorbance of the controls without cells was subtracted from the mean absorbances. Statistical analysis was performed using the software Graphpad Prism 5 (GraphPad Software, Inc., La Jolla, CA, USA). For differences between each test specimens and the negative control, unpaired $t$-tests were performed. All tests were two-tailed and the statistically significant level was set at 0.05 .

\section{Results}

In vitro characterization of bone substitute materials. All tested bone substitute materials showed satisfactory cytocompatibility with viability $>70 \%$ of the negative control in the indirect assay, which indicates the non-toxic 

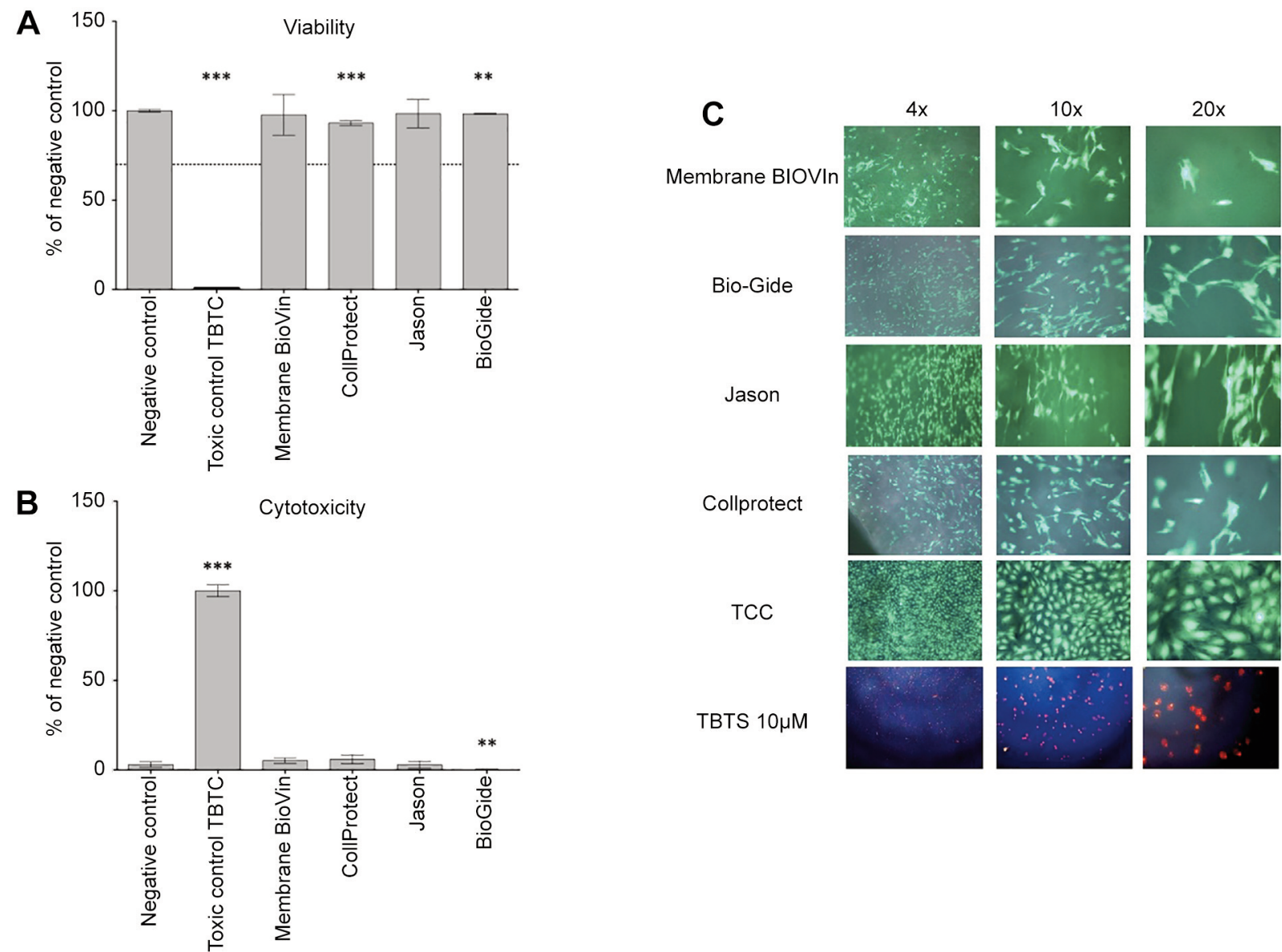

Figure 2. Cytocompatibility of membranes. A) Viability B) Cytotoxicity. The mean absorbance of controls without cells was subtracted from the mean absorbances. Columns represent mean values of quadruplicate measurements; error bars represent the standard deviation. The dotted line shows $70 \%$ of the negative control. Assays were performed following a $24 \mathrm{~h}$ incubation of MC3T3 cells with extracts of the materials. *,** and ***: Significantly different from the negative control at $p \leq 0.05, p \leq 0.01$ and $p \leq 0.001$, respectively. C) Live-dead staining assay. Double staining with fluoresceindiacetate (FDA) and propidium iodide (PI) was performed on MC3T3 cells that were directly seeded and cultured for $24 \mathrm{~h}$ on the membrane specimens. The green dye FDA exclusively stains viable cells, dead cells with compromised plasma membrane integrity are stained by the red dye PI. Left, middle and right panels show images generated using a $4 \times, 10 \times$, and a $20 \times$ objective, respectively.

range as defined in DIN EN ISO 10993-5:2009 (Figure 1A). In concordance, no cytotoxicity was detected for any of the tested bone substitute materials. The values in the LDH-assay were in a similar range as the negative control (cells incubated with cell culture medium) (Figure 1B). Although cytotoxicity was low for all tested bone substitute materials (range $=3-10 \%$ of the toxic control), BIOVIn, OTOss and Nanobone were significantly different from the negative control with $p \leq 0.05, p \leq 0.001$ and $p \leq 0.05$, respectively. With viability around $70 \%$ of the negative control, cells incubated in extracts of two of the assessed bone substitute materials (BIOVin, OTOss) showed lower viability than cells incubated in extracts of all other tested materials (around $100 \%$ of the negative control). Even though these values are significantly different from the negative control ( $p \leq 0.001)$, they still fall within the non-toxic range.

In vitro characterization of membranes. All tested membranes showed satisfactory cytocompatibility with viability $>70 \%$ of the negative control in the indirect assay (Figure 2A). In concordance, no cytotoxicity was detected for any of the tested membranes in the indirect LDH assay. The values in the LDHassay were in a similar range as the negative control (cells incubated with cell culture medium) (Figure 2B). Although viability was very similar to the negative control for all tested materials (range=93-98\%), Collprotect showed significantly lower viability $(p \leq 0.001)$ and Bio-Gide showed significantly lower viability $(p \leq 0.01)$ as well as a significantly lower cytotoxicity $(p \leq 0.01)$ when compared to the negative control. 
Large numbers of green fluorescein diacetate (FDA) positive vital cells and only sporadic red propidium iodide (PI) positive dead cells were visible on all tested membranes and on the non-toxic control material TCC (Figure 2C), confirming good cytocompatibility. The cells on all membranes exhibited elongated, cell type characteristic morphologies, suggesting firm adherence to the materials.

\section{Discussion}

Clinical success of biomaterials is strongly associated with a sufficient biocompatibility (12). In this study, we assessed 7 different bone substitute materials and 4 membranes using present, international standards (DIN EN ISO 10993-5:2009) and an established pre-osteoblast cell line (MC3T3). EN ISO 10993-5:2009 defines viability $\geq 70 \%$ relative to the negative control as nontoxic. Although we found minor differences in cytocompatibility among the assessed materials, all tested materials can be considered as cytocompatible.

The examined BSMs are of different origin, mechanical and structural property. A unifying factor is their common objective to regenerate human bone in structure and function. Human bone is comprised of 25\% organic substances (collagen type I), $65 \%$ inorganic matrix (hydroxyapatite) and $10 \%$ water, all together contributing to its unique qualities $(7,8)$.

As indicated above, autologous bone grafts have a standalone position in bone regeneration approaches. Nevertheless, promising natural alternatives are allogenic and xenogenic grafts. Former grafts can be derived from either living donations or corpses. The tested specimens from BIOVin, Bio-Oss and Cerabone belong to the latter, xenogenic category. They are produced from bovine bones and therefore, mainly consist of natural and mechanically stable inorganic hydroxyapatite (HA). The feared risk of a "slow virus" transmission, e.g., Bovine spongiform encephalopathy (BSE) is almost excluded due to their manufacturing process. Notably, some xenogenic materials can contain additives that may enhance their properties, e.g., BIOVin includes based on manufacturer's information a bioactive microcoat, composed of polymers and cell nutrients.

Moreover, the synthetic specimens used in our study such as Cerasorb, Otoss, and Maxresorb have a foundation of $\beta$ Tricalcium-phosphate and ceramics. Natural and synthetic BSMs can therefore serve as leading scaffolds for osteoblasts and thus, act osteoconductively $(7,8)$. Still, they have minor osteogenic and osteoinductive properties (13-15) (Table II).

In contrast, composite materials were created to overcome disadvantages of common synthetic materials, by ideally promoting osteoinductive properties. They are comprised of a carrier material such as an osteoconductive scaffold, osteogenic cells and/or bone morphogenic proteins (BMPs) $(14,16-18)$. Nanobone is a composite material, containing $76 \% \mathrm{HA}$ and $24 \%$ silicon dioxide ( $\mathrm{SiO} 2)$. In vivo experiments for Nanobone observed the formation of trabecular bone after
5 weeks and a complete degradation of the material after eight months (17). In clinical practice, the use of BSMs and membranes can provide adequate bone regeneration depending on the prevailing bone and volume defect (19). Despite the individual decision of which material can offer the best treatment to different patients' indication, protection against inflammatory reactions should be of first priority.

Our study is limited in scope to an in vitro assessment of bone substitute materials and membranes. To assess whether the observed minor differences can impact regenerative processes, further in vivo studies need to be conducted.

\section{Conclusion}

The increasing demand for bone substitute materials in oral and maxillofacial surgery is the reason for expanding research into developing biocompatible bone substitute materials and membranes that can reduce donor site morbidity and infection risk. The prerequisite for the clinical use of the materials are standardized tests to assess the materials' required harmlessness in clinical application and biocompatibility in application. This preclinical investigation provides evidence of cytocompatibility of the materials examined.

\section{Conflicts of Interest}

OT Medical GmbH provided the test specimens for the experimental investigation. The design, documentation, and analyses of this study were completed entirely independent of OT Medical. The Authors declare that they have no conflicts of interest to report.

\section{Authors' Contributions}

Schäfer S: data analysis; interpretation; drafted the manuscript. AlQaddo H: data collection; critical revision; approval of the article; Gosau M: critical revision; approval of the article. Smeets R: concept; critical revision; approval of the article. Hartjen P: concept; design; data collection; data analysis; critical revision of the article; Friedrich R: critical revision; approval of the article. Nada OA: data collection; data analysis; critical revision; approval of the article. Vollkommer T: critical revision; approval of the article. Rashad A: critical revision; approval of the article.

\section{Acknowledgements}

The Authors gratefully acknowledge Jane Rehberg for her excellent technical support.

The Authors thank OT Medical GmbH (Bremen, Germany) for providing the materials and funding for the experimental investigation.

\section{References}

1 Historical population data and projections (1950-2050). Organisation for economic cooperation and development 2015. Available at: https://stats.oecd.org/Index.aspx?DataSetCode= POP_PROJ [Last accessed on April 10, 2021] 
2 Trajkovski B, Jaunich M, Müller WD, Beuer F, Zafiropoulos GG and Houshmand A: Hydrophilicity, viscoelastic, and physicochemical properties variations in Dental Bone Grafting Substitutes. Materials (Basel) 11(2): 215, 2018. PMID: 29385747. DOI: 10.3390/ma11020215

3 Griffin K, Davis K, Mckinley T, Anglen J, Chu T, Boerckel J and Kacena M: Evolution of Bone Grafting: bone grafts and tissue engineering strategies for vascularized bone regeneration. Clinical Reviews in Bone and Mineral Metabolism 13(4): 232244, 2020. DOI: 10.1007/s12018-015-9194-9

4 Donati $\mathrm{D}$, Zolezzi C, Tomba $\mathrm{P}$ and Viganò $\mathrm{A}$ : Bone grafting: historical and conceptual review, starting with an old manuscript by Vittorio Putti. Acta Orthop 78(1): 19-25, 2007. PMID: 17453388. DOI: $10.1080 / 17453670610013376$

5 Kolk A, Handschel J, Drescher W, Rothamel D, Kloss F, Blessmann M, Heiland M, Wolff KD and Smeets R: Current trends and future perspectives of bone substitute materials - from space holders to innovative biomaterials. J Craniomaxillofac Surg 40(8): 706-718, 2012. PMID: 22297272. DOI: 10.1016/ j.jcms.2012.01.002

6 TMR: Dental membrane and bone graft substitutes market. Available at: https://www.transparencymarketresearch.com/ dental-membrane-bone-graft-substitutes-market.html [Last accessed on April 21, 2021]

7 Smeets R, Hanken H, Jung O, Rothamel D, Handschel J, Al-dam A, Blessmann M, Heiland M and Kolk A: Knochenersatzmaterialien. Der Freie Zahnarzt 58(10): 78-88, 2020. DOI: 10.1007/s12614-0141989-4

8 Smeets R, Hanken H, Beck-broichsitter B, Gröbe A, Precht C, Heiland $\mathrm{M}$ and Jung O: Knochenersatzmaterialien. Der Freie Zahnarzt 60(5): 76-87, 2020. DOI: 10.1007/s12614-015-5461-x

9 Sheikh Z, Javaid MA, Hamdan N and Hashmi R: Bone regeneration using bone morphogenetic proteins and various biomaterial carriers. Materials (Basel) 8(4): 1778-1816, 2015. PMID: 28788032. DOI: 10.3390/ma8041778

10 Bhatia SK and Yetter AB: Correlation of visual in vitro cytotoxicity ratings of biomaterials with quantitative in vitro cell viability measurements. Cell Biol Toxicol 24(4): 315-319, 2008. PMID: 17932777. DOI: $10.1007 / \mathrm{s} 10565-007-9040-\mathrm{z}$

11 Jung O, Smeets R, Porchetta D, Kopp A, Ptock C, Müller U, Heiland M, Schwade M, Behr B, Kröger N, Kluwe L, Hanken $\mathrm{H}$ and Hartjen P: Optimized in vitro procedure for assessing the cytocompatibility of magnesium-based biomaterials. Acta Biomater 23: 354-363, 2015. PMID: 26073090. DOI: 10.1016/ j.actbio.2015.06.005
12 Murray PE, García Godoy C and García Godoy F: How is the biocompatibilty of dental biomaterials evaluated? Med Oral Patol Oral Cir Bucal 12(3): E258-E266, 2007. PMID: 17468726.

13 Takagi S, Chow LC, Markovic M, Friedman CD and Costantino PD: Morphological and phase characterizations of retrieved calcium phosphate cement implants. J Biomed Mater Res 58(1): 36-41, 2001. PMID: 11152995. DOI: 10.1002/10974636(2001)58:1<36::aid-jbm50>3.0.co;2-\#

14 Cipitria A, Reichert JC, Epari DR, Saifzadeh S, Berner A, Schell H, Mehta M, Schuetz MA, Duda GN and Hutmacher DW: Polycaprolactone scaffold and reduced rhBMP-7 dose for the regeneration of critical-sized defects in sheep tibiae. Biomaterials 34(38): 9960-9968, 2013. PMID: 24075478. DOI: 10.1016/j.biomaterials.2013.09.011

15 Schliephake H, Zghoul N, Jäger V, van Griensven M, Zeichen J, Gelinsky M and Szubtarsky N: Bone formation in trabecular bone cell seeded scaffolds used for reconstruction of the rat mandible. Int J Oral Maxillofac Surg 38(2): 166-172, 2009. PMID: 19121923. DOI: 10.1016/j.ijom.2008.11.018

16 Mai R, Reinstorf A, Pilling E, Hlawitschka M, Jung R, Gelinsky M, Schneider M, Loukota R, Pompe W, Eckelt U and Stadlinger B: Histologic study of incorporation and resorption of a bone cement-collagen composite: an in vivo study in the minipig. Oral Surg Oral Med Oral Pathol Oral Radiol Endod 105(3): e9-14, 2008. PMID: 18280955. DOI: 10.1016/j.tripleo.2007.09.016

17 Abshagen K, Schrodi I, Gerber T and Vollmar B: In vivo analysis of biocompatibility and vascularization of the synthetic bone grafting substitute NanoBone. J Biomed Mater Res A 91(2): 557-566, 2009. PMID: 18985779. DOI: 10.1002/ jbm.a.32237

18 Ren J, Blackwood KA, Doustgani A, Poh PP, Steck R, Stevens MM and Woodruff MA: Melt-electrospun polycaprolactone strontium-substituted bioactive glass scaffolds for bone regeneration. J Biomed Mater Res A 102(9): 3140-3153, 2014. PMID: 24133006. DOI: 10.1002/jbm.a.34985

19 Kaneko A, Marukawa E and Harada H: Hydroxyapatite nanoparticles as injectable bone substitute material in a vertical bone augmentation model. In Vivo 34(3): 1053-1061, 2020. PMID: 32354892. DOI: 10.21873/invivo.11875

Received March 11, 2021

Revised April 20, 2021

Accepted April 21, 2021 